http://jurnaltarbiyah.uinsu.ac.id/index.php/raudhah

e-mail: jurnalraudhah@uinsu.ac.id

p-ISSN: 2338-2163

e-ISSN: $2716-2435$

\title{
Metode Bercerita Kisah Nabi dan Pengaruhnya Terhadap Perkembangan Akhlak Anak di RA Hamdaniyah
}

\author{
${ }^{1}$ Hadis Purba \\ Universitas Islam Negeri Sumatera Utara \\ email: hadispurba@uinsu.ac.id \\ ${ }^{2}$ Raisah Armayanti Nasution \\ Universitas Islam Negeri Sumatera Utara \\ email: raisaharmayantinasution@uinsu.ac.id \\ ${ }^{3}$ Rosita \\ Universitas Islam Negeri Sumatera Utara \\ email: itaros1463@gmail.com
}

$\begin{array}{lll}\text { Article received }: 5 \text { November } 2020 & \text { Review process } & : 8 \text { Januari } 2021 \\ \text { Article accepted }: 18 \text { Januari } 2021 & \text { Article published }: 8 \text { Maret } 2021\end{array}$

\begin{abstract}
Abstrak
Penelitian ini bertujuan untuk mengetahui pengaruh metode bercerita Kisah Nabi terhadap perkembangan akhlak anak usia 5-6 tahun. Penelitian yang digunakan yaitu pendekatan kuantitatif dengan Quasi Eksperimen Design. Sampel pada penelitian ini berjumlah 30 orang anak usia 5-6 tahun di RA Hamdaniyah. Instrumen penelitian ini menggunakan lembar observasi. Teknik analisis data pada penelitian ini yaitu uji hipotesis menggunakan rumus uji-t untuk data homogen. Penelitian ini membuktikan bahwa: terdapat pengaruh metode bercerita terhadap perkembangan akhlak anak usia 5-6 tahun di RA Hamdaniyah. Temuan lain penelitian ini yaitu anak merasa senang ketika belajar, bahkan menimbulkan emosi dan sikap sosial yang baik ketika guru menceritakan kisah Nabi sebagai tauladan umat dalam bersikap. Dengan demikian, penelitian ini membuktikan pentingnya penggunaan metode bercerita kisah Nabi khususnya pada sekolah yang berbasis Islam seperti Raudhatul Athfal.
\end{abstract}

Kata kunci: Metode bercerita kisah nabi; Metode pemberian tugas; Perkembangan akhlak

\begin{abstract}
This study aims to determine the effect of story telling method about Prophet's on the moral development of children aged 5-6 years. The research used is a quantitative approach with a Quasi Experiment Design. The sample in this study amounted to 30 children aged 5-6 years at RA Hamdaniyah. The research instrument used an observation sheet. The data analysis technique in this study is to test the hypothesis using the t-test formula for homogeneous data. This research proves that: there is an effect of the storytelling method on the moral development of children aged 5-6 years in RA Hamdaniyah. Another finding of this study is that children feel happy when learning, and even generate good emotions and social attitudes when the teacher tells the story of the Prophet as a role model for the people. Thus, this study proves the importance of using story telling method about Prophet, especially in Islamic-based schools such as Raudhatul Athfal.
\end{abstract}

Keywords: Story telling method about prophet; Assignment method; Moral development 
http://jurnaltarbiyah.uinsu.ac.id/index.php/raudhah

e-mail: jurnalraudhah@uinsu.ac.id

p-ISSN: 2338-2163

e-ISSN: $2716-2435$

\section{A. PENDAHULUAN}

Anak usia dini menurut (Khadijah, 2016) adalah anak yang dilahirkan sampai umur 6 tahun. Pada umur ini sangat menentukan dalam pembentukan jati diri anak dimana anak akan memasuki fase tumbuh- kembang secara fisik maupun nonfisik maka usia ini dapat dinamakan (Golden Age). Pada dasarnya anak membutuhkan sebuah stimulus yang dapat membantu tumbuh kembang yang ada pada dirinya. Menurut (Suyadi \& Maulidya, 2015) Pendidikan Anak Usia Dini (PAUD) adalah pembinaan yang dilakukan untuk memenuhi tumbuh kembang pada anak secara keseluruhan yang ada pada aspek kepribadian anak. Maka dari itu, pembinaan ini memberi kesempatan kepada anak agar dapat mengembangkan kepribadian dan potensi yang ada. Konsekuensinya, penyelenggaran pendidikan harus mempersiapkan berbagai aspek perkembangan anak yaitu kognitif, bahasa, moral, sosial, fisik dan motorik.

Setiap anak yang lahir semuanya dalam keadaan suci atau kosong, tetapi anak sudah dibekali dengan pendengaran, penglihatan dan juga hati sehingga dapat dikatakan potensi yang dibawanya dari anak tersebut lahir dikembangkan setelah dilahirkannya ke dunia. Dalam mengembangkan potensi yang ada pada anak maka dibutuhkan didikan yang pastinya sesuai dengan nilai atau norma yang ada dan disesuaikan dengan kemampuan yang dipunya pada anak. (Abdurrahman, 2018)

Dalam hal ini, (Syafaruddin, 2011) menyatakan bahwa setiap pendidik wajib melihat cara pendidikan agama Islam bagi anak usia dini agar anak betul-betul terarah perkembangan jiwanya. Karena anak yang lahir keadaan fitrah/kosong dan disini sebagai pendidik, wajib memberikan stimulus yang baik, karena anak memiliki sifat peniru dan anak dapat menirukan sesuatu sesuai dengan apa yang dilihat bisa saja sifat baik ataupun buruk. (Saepudin \& Sudiarni, 2014) mengemukakan bahwa pendidikan akhlak dan pembinaan karakter merupakan hal penting yang harus diterapkan pada anak usia dini, dan hal tersebut dapat dilakukan dengan menerapkan metode bercerita.

(Suryana, 2014) berpendapat bahwa usia dini saat yang paling baik bagi guru untuk meletakkan dasar-dasar pendidikan nilai moral dan agama kepada anak usia dini. Oleh karena itu seorang guru harus selalu berupaya dengan berbagai cara agar dapat membimbing anak usia dini mempunyai kepribadian yang baik dan dilandasi dengan nilai 
http://jurnaltarbiyah.uinsu.ac.id/index.php/raudhah

moral dan agama anak. Dengan diberikannya landasan pendidikan akhlak dan agama kepada anak, seorang anak dapat membedakan perilaku yang benar dan salah.

Biasanya guru dalam mengajarkan pendidikan akhlak kepada anak dengan menggunakan metode bercerita, karena pada dasarnya, anak-anak suka dengan cerita, apalagi guru membawakan cerita tersebut dengan menarik sehingga timbullah rasa penasaran anak tentang cerita yang akan dibawakan oleh gurunya. Dan cerita tersebut harus ada nilai-nilai pendidikan akhlaknya sehingga anak tersebut bisa berpikir dan menjalankan hal-hal yang positif.

Pada kenyataanya saat penulis melakukan observasi di Raudhatul Athfal (RA) Hamdaniyah pada kelompok $\mathrm{B}$, terdapat beberapa masalah yang berkaitan dengan perkembangan akhlak anak seperti beberapa anak tidak mengikuti perintah gurunya, sebagian anak tidak mau mengantri ketika bersalaman kepada gurunya, sebagian anak tidak mau mengerjakan tugas dari guru, metode bercerita yang kurang diterapkan, serta media pembelajaran yang digunakan kurang memadai. Maka dari itu, dibutuhkan suatu cara agar dapat mempengaruhi perkembangan akhlak pada anak yaitu dengan metode bercerita.

Metode bercerita menurut (Mursid, 2015) adalah salah satu metode yang banyak digunakan di Pendidikan Anak Usia Dini (PAUD). Metode tersebut dapat memberikan pengalaman belajar bagi anak PAUD dengan membawakan cerita kepada anak secara lisan. Dalam kegiatan bercerita anak dibimbing mengembangkan kemampuan untuk mendengarkan cerita guru yang bertujuan untuk memberikan informasi atau menanamkan nilai-nilai sosial, moral dan keagamaan. Nilai- nilai moral yang dapat ditanamkan pada anak yakni bagaimana seharusnya sikap moral seseorang yang diwujudkan dalam kehidupan sehari-hari. Hasil penelitian (Abdul \& Mamonto, 2016) membuktikan bahwa terdapat pengaruh dan perbedaan yang signifikan antara kemampuan menyimak anak sebelum perlakuan dan kemampuan menyimak anak sesudah perlakuan di Kota Selatan Gorontalo. Penelitian yang dilakukan (Fatmawati, 2018) membuktikan bahwa metode bercerita berpengaruh signifikan terhadap perkembangan norma agama dan moral siswa di RA Perwanida Raci 
http://jurnaltarbiyah.uinsu.ac.id/index.php/raudhah

e-mail: jurnalraudhah@uinsu.ac.id

p-ISSN: 2338-2163

e-ISSN: $2716-2435$

Berdasarkan penelitian terdahulu tersebut bahwa hasil penelitiannya sama-sama menerapkan metode bercerita dengan dan latar belakang di atas maka penulis tertarik mengambil judul Pengaruh Metode Bercerita Kisah Nabi Terhadap Perkembangan Akhlak Anak Usia 5-6 Tahun.

\section{B. METODE PENELITIAN}

Penelitian ini dilaksanakan di RA Hamdaniyah Kec. Medan Tembung Kota Medan. Metode yang digunakan pada penelitian ini yaitu penelitian kuantitatif dengan desain penelitian Quasi Eksperiment. Pada penelitian ini diterapkan dua metode pembelajaran, yaitu metode bercerita kisah nabi dan metode pemberian tugas. Metode bercerita kisah nabi merupakan treatment pada penelitian ini yang diterapkan di kelas eksperimen, sedangkan metode pemberian tugas merupakan pembelajaran yang biasa digunakan di RA Hamaniyah selanjutnya disebut sebagai kelas kontrol.

Populasi pada penelitian ini yaitu seluruh anak usia 5-6 tahun di RA Hamdaniyah yang berjumlah 30 orang anak dan terdistribusi pada dua kelas yang terpisah. Karena penelitian ini membutuhkan dua kelas (kelas eksperimen dan kelas kontrol), maka digunakan teknik boring sampling menurut (Maisarah, 2017) jumlah populasi dan sampel dalam penelitian ini sama. Dengan demikian, sampel pada penelitian ini yaitu 30 orang anak usia 5-6 tahun yang terdistribusi masing-masing sebanyak 15 orang anak pada kelas eksperimen dan 15 orang anak pada kelas kontrol. Dalam menentukan kelas eksperimen dan kelas kontrol, dilakukan undian dengan membuat dua kertas gulungan yang ada tulisan eksperimen dan kontrol secara terpisah, kemudian guru kelas mengambil satu kertas gulungan untuk menentukan peran kelasnya di dalam penelitian ini.

Pada penelitian ini menggunakan teknik pengumpulan data berupa observasi terstruktur dan instrumennya yaitu lembar observasi beserta rubrik penilaiannya. Setelah data diperoleh kemudian diolah dengan teknik analisis data. Teknik analisis data pada penelitian ini yaitu uji hipotesis menggunakan rumus uji-t untuk data homogen yang rumusnya menurut (Jaya, 2018; Maisarah, 2019) yaitu sebagai berikut: 
http://jurnaltarbiyah.uinsu.ac.id/index.php/raudhah

e-mail: jurnalraudhah@uinsu.ac.id

p-ISSN: 2338-2163

e-ISSN: $2716-2435$

$$
t_{\text {hitung }}=\frac{\bar{x}_{1}-\bar{x}_{2}}{\sigma^{2} \sqrt{\frac{1}{n_{1}}+\frac{1}{n_{2}}}}
$$

Keterangan :

$\sigma^{2} \quad$ : koefisien varians

$\bar{X}_{1}$ : koefisien mean (rata-rata) kelompok 1

$\bar{X}_{2}$ : koefisien mean (rata-rata) kelompok 2

$\mathrm{n}_{1} \quad$ : banyak data kelompok 1

$\mathrm{n}_{2}$ : banyak data kelompok 2

\section{HASIL TEMUAN DAN PEMBAHASAN}

Data penelitian ini dikumpulkan dengan menggunakan observasi. Lembar observasi yang sudah disusun dipakai untuk mengamati perkembangan akhlak anak. Saat kegiatan berlangsung anak diobservasi dengan menggunakan instrumen yang telah dipersiapkan. Untuk mengetahui gambaran tentang karakteristik data dan hasil observasi yang dilaksanakan pada kegiatan tersebut. Pada kelas eksperimen menggunakan metode bercerita Kisah Nabi yang berjumlah 15 anak sedangkan kelas kontrol menggunakan metode pemberian tugas yang berjumlah 15 anak. Pada penelitian yang menggunakan metode bercerita Kisah Nabi pada kelas eksperimen sebelumnya diadakan penelitian dahulu dilakukan pretes atau tes awal. Tujuannya adalah untuk mengetahui pengaruh metode bercerita Kisah Nabi terhadap perkembangan akhlak anak usia 5-6 tahun.

\section{Data Pretes Perkembangan Akhlak Anak Usia 5-6 Tahun}

Dari pengujian nilai pretes kelas eksperimen dan kelas kontrol memperoleh kemampuan awal yang sama (normal). Berikut ini ringkasan hasil pretes kelas eksperimen dan kelas kontrol pada tabel 1:

Tabel 1. Hasil Pretes Perkembangan Akhlak

\begin{tabular}{|c|c|c|}
\hline \multirow{2}{*}{ Statistik } & \multicolumn{2}{|c|}{ Skor Pretes di kelas } \\
\cline { 2 - 3 } & Eksperimen & Kontrol \\
\hline Jumlah & 931,19 & 883,29 \\
\hline Rata-rata & 62,079 & 58,886 \\
\hline
\end{tabular}


http://jurnaltarbiyah.uinsu.ac.id/index.php/raudhah

e-mail: jurnalraudhah@uinsu.ac.id

p-ISSN: 2338-2163

e-ISSN: $2716-2435$

\begin{tabular}{|c|c|c|}
\hline \multirow{2}{*}{ Statistik } & \multicolumn{2}{|c|}{ Skor Pretes di kelas } \\
\cline { 2 - 3 } & Eksperimen & Kontrol \\
\hline Simpangan baku & 3,168 & 2,995 \\
\hline Varians & 10,041 & 8,975 \\
\hline Skor tertinggi & 66,66 & 62,50 \\
\hline Skor terendah & 58,83 & 54,16 \\
\hline
\end{tabular}

Pada tabel 1 terbukti bahwa di kelas eksperimen dan kelas kontrol mempunyai skor pretes yang tidak jauh berbeda. Hal tersebut menandakan bahwa perkembangan akhlak anak sama sebelum kedua metode diterapkan. Rata-rata pretes di kelas eksperimen yaitu 62,079 dan pada kelas kontrol yaitu 58,886, perbedaan rata-rata keduanya yaitu 3,193. Simpangan baku pada kelas eksperimen yaitu 3,168 dan di kelas kontrol 2,995, perbedaan pada simpang baku keduanya yaitu 0,173 . Varians di kelas eksperimen 10,041 di kelas kontrol 8,975, perbedaan varians pada keduanya yaitu 1,066. Begitupun pada perolehan skor tertinggi dan terendah di kelas eksperimen dan kelas kontrol yang selisihnya tidak besar, sekitar 4-5 skor. Sehingga data postes jika treatment diterapkan pada salah satu kelas (yaitu kelas eksperimen) dapat digunakan secara utuh untuk menggeneralisasikan hipotesis yang terbukti.

\section{Data Postes Perkembangan Akhlak Anak Usia 5-6 Tahun}

Setelah diperoleh data pretes, maka kedua kelas tersebut menerapkan metode yang berbeda, yaitu: metode bercerita kisah nabi diterapkan pada anak usia 5-6 tahun di kelas eksperimen dan metode pemberian tugas diterapkan pada anak usia 5-6 tahun di kelas kontrol. Setelah kedua metode diterapkan sesuai rencana pelaksanaan pembelajaran harian dengan kegiatan dan karakteristik pembelajaran yang berbeda, maka dilakukan postes untuk memperoleh data akhir yang diuji menggunakan rumus uji-t. Hasil postes perkembangan akhlak di kelas eksperimen dan kontrol disajikan pada tabel 2: 
http://jurnaltarbiyah.uinsu.ac.id/index.php/raudhah

e-mail: jurnalraudhah@uinsu.ac.id

p-ISSN: 2338-2163

e-ISSN: $2716-2435$

Tabel 2. Hasil Postes Perkembangan Akhlak

\begin{tabular}{|c|c|c|}
\hline \multirow{2}{*}{ Statistik } & \multicolumn{2}{|c|}{ Skor Postes di kelas } \\
\cline { 2 - 3 } & Eksperimen & Kontrol \\
\hline Jumlah & 1289,5 & 1079,1 \\
\hline Rata-rata & 85,97 & 71,94 \\
\hline Simpangan baku & 4,486 & 3,420 \\
\hline Varians & 20,128 & 11,703 \\
\hline Skor tertinggi & 93,75 & 77,08 \\
\hline Skor terendah & 81,25 & 66,66 \\
\hline
\end{tabular}

Pada tabel 2 diperoleh skor rata-rata postes di kelas eksperimen yaitu 85, 97 lebih besar dari pada kelas kontrol yaitu 71,94. Selisih rata-rata skor pada kedua kelas tersebut mencapai skor 14,03. Untuk perbandingan atau selisih simpangan baku pada kelas eksperimen dan kontrol tidak jauh beda, yaitu hanya 1,066 dengan skor sebesar 4,486 di kelas eksperimen dan 3,420 di kelas kontrol. Sedangkan skor varians terlihat jauh berbeda, skor varians postes di kelas eksperimen mencapai 20,128 sedangkan di kelas kontrol hanya 11,703 sehingga selisih skor varians pada kedua kelas tersebut yakni sebesar 8,425. Namun perbedaan skor varians belum tentu membuktikan bahwa varians datanya heterogen, sehingga data postes diuji homogenitasnya sebelum menguji hipotesis menggunakan uji-t untuk data homogen.

\section{Analisis Data Hasil Penelitian}

Sebelum dilakukan uji hipotesis terlebih dahulu uji prasyarat yaitu uji normalitas dengan menggunakan rumus liliefors yang bertujuan untuk mengetahui data penelitian memiliki sebaran data yang berdistribusi normal atau tidak. Sampel berdistribusi normal jika dipenuhi $\mathrm{L}_{\mathrm{O}}<\mathrm{L}_{\text {tabel }}$ pada taraf signifikan $\alpha=0,05$. Hasil uji normalitas ditunjukkan pada tabel 3: 
http://jurnaltarbiyah.uinsu.ac.id/index.php/raudhah

e-mail: jurnalraudhah@uinsu.ac.id

p-ISSN: 2338-2163

e-ISSN: $2716-2435$

Tabel 3. Data Hasil Uji Normalitas

\begin{tabular}{|l|c|l|l|c|l|l|}
\hline \multirow{2}{*}{ Kelas } & \multicolumn{3}{|c|}{ Pretes } & \multicolumn{3}{c|}{ Postes } \\
\cline { 2 - 7 } & $\mathrm{L}_{\mathbf{O}}$ & Ltabel & Keterangan & $\mathrm{L}_{\mathbf{O}}$ & Ltabel & Keterangan \\
\hline Eksperimen & 0,1675 & 0,220 & Normal & 0,1885 & 0,220 & Normal \\
\hline Kontrol & 0,1438 & 0,220 & Normal & 0,1606 & 0,220 & Normal \\
\hline
\end{tabular}

Tabel 3 membuktikan bahwa data pretes dan postes di kelas eksperimen maupun kontrol mempunyai sebaran data yang normal atau biasa disebut dengan data berdistribusi normal. Hal tersebut karena skor $\mathrm{L}_{0}$ lebih rendah dari 0,220 sehingga $\mathrm{H}_{0}$ diterima dan $\mathrm{H}_{\mathrm{a}}$ ditolak. Setelah membuktikan normalitas data untuk memenuhi asumsi parametrik, maka selanjutnya dilakukan uji homogenitas data untuk mengetahui varians data penelitian berasal dari populasi yang homogen atau tidak. Untuk pengujian homogenitas digunakan uji kesamaan kedua varians menggunakan rumus uji Fisher. Jika Fhitung < Ftabel maka $\mathrm{H}_{0}$ diterima dan $\mathrm{H}_{\mathrm{a}}$ ditolak. Dengan derajat kebebasan pembilang $=\mathrm{n}_{1}-1$ dan derajat kebebasan penyebut $n_{2}-1$ dengan taraf nyata $\alpha=0,05$. Hasil uji homogenitas data di kelas eksperimen dan kontrol disajikan pada tabel 4:

Tabel 4. Data Hasil Uji Homogenitas

\begin{tabular}{|l|l|l|l|l|l|}
\hline Data & $\begin{array}{c}\text { Varians } \\
\text { terbesar }\end{array}$ & $\begin{array}{c}\text { Varians } \\
\text { terkecil }\end{array}$ & Fhitung & Ftabel & Kesimpulan \\
\hline Pretes & 10,041 & 8,975 & 1,118 & 2,484 & Homogen \\
\hline Postes & 20,128 & 11,703 & 1,719 & 2,484 & Homogen \\
\hline
\end{tabular}

Tabel 4 membuktikan bahwa data pretes dan postes di kelas eksperimen maupun kontrol mempunyai varians data yang homogen atau biasa disebut dengan data berasal dari populasi yang homogen. Hal tersebut karena skor $F_{\text {hitung }}$ lebih rendah dari $F_{\text {tabel }}(=2,484)$ sehingga $\mathrm{H}_{0}$ diterima dan $\mathrm{H}_{\mathrm{a}}$ ditolak. Setelah diketahui bahwa kelas eksperimen dan kelas kontrol berdistribusi normal dan bervarians homogen, selanjutnya dilakukan uji hipotesis yang menggunakan rumus uji-t untuk da ta homogen. Uji hipotesis dilakukan uji satu pihak sehingga kriteria untuk menerima atau menolak $\mathrm{H}_{0}$ yaitu jika thitung > pada taraf nyata $\alpha=0,050, \mathrm{H}_{\mathrm{a}}$ diterima dan $\mathrm{H}_{0}$ ditolak. Diperoleh nilai thitung $=13,628$ dengan 
http://jurnaltarbiyah.uinsu.ac.id/index.php/raudhah

e-mail: jurnalraudhah@uinsu.ac.id

p-ISSN: 2338-2163

e-ISSN: $2716-2435$

taraf $\alpha=0,050$ serta dapat dilihat pada tabel dt 13 diperoleh nilai tabel 2,160. Karena thitung $>$ tabel, maka $\mathrm{H}_{0}$ ditolak dan $\mathrm{H}_{\mathrm{a}}$ diterima. Dapat disimpulkan bahwa terdapat pengaruh metode bercerita Kisah Nabi terhadap perkembangan akhlak anak usia 5-6 tahun di RA Hamdaniyah.

\section{Pengaruh Metode Bercerita Kisah Nabi Terhadap Perkembangan Akhlak Anak Usia 5-6 Tahun di RA Hamdaniyah}

Pada penelitian ini diterapkan dua metode pembelajaran pada kelas yang berbeda di RA Hamdaniyah, yaitu metode bercerita kisah nabi yang diterapkan pada kelas eksperimen dan metode pemberian tugas pada kelas kontrol. Pada pelaksanaan metode bercerita di kelas eksperimen membuat anak antusias guru karena menggunakan alat peraga, dan terlihat respon yang baik pada perkembangan akhlak anak, seperti: anak menyimak dengan baik dan serius ketika guru menceritakan kisah nabi pada kelas eksperimen, respon anak terlihat senang dan berkomunikasi dengan sopan, anak mampu menjawab atau bertanya perihal sikap para nabi, bahkan anak mengikuti atau mentauladani sikap para nabi. Hal tersebut mencirikan bahwa akhlak pada diri anak usia 5-6 tahun di RA Hamdaniyah mulai berkembang dan secara senang meniru sikap nabi yang dikisahkan ketika pembelajaran berlangsung. Sedangkan pada pelaksanaan metode pemberian tugas, terlihat anak yang mau mengerjakan tugas dari guru namun masih terlihat beberapa anak yang merasa bosan, beberapa anak bahkan tidak tertarik untuk mengerjakan tugas walaupun guru sudah menerapkan teori behaviorisme dimana anak akan diberikan hadiah jika mengerjakan kewajibannya.

Perbedaan tersebut menyiratkan bahwa perkembangan anak lebih baik pada kelas ekperimen, bukan hanya perkembangan akhlaknya tetapi juga perkembangan sosial emosional karena terjadi interaksi edukatif pada saat guru menceritakan kisah nabi dan emosi anak lebih teratur, kognitif anak juga ikut berkembang karena anak mengetahui halhal baru dari kisah nabi yang dipelajari. Namun bukan berarti pada kelas kontrol yang menerapkan metode pemberian tugas tidak memberikan dampak positif pada perkembangan anak khususnya perkembangan akhlak. Pada tabel 2 diperoleh skor ratarata postes di kelas eksperimen yaitu 85, 97 dan di kelas kontrol yaitu 71,94. Pada tabel 
http://jurnaltarbiyah.uinsu.ac.id/index.php/raudhah

1 diperoleh rata-rata pretes di kelas eksperimen yaitu 62,079 dan di kelas kontrol yaitu 58,886. Jika dianalisis selisih skor pretes dan postes pada masing-masing kelas akan terbukti bahwa kedua kelas memberikan pengaruh terdapat nilai perkembangan akhlak anak usia 5-6 tahun di RA Hamdaniyah, walau terlihat selisih skor postes dan pretes di kelas eksperimen $(23,891)$ lebih besar daripada kelas kontrol $(13,054)$.

Skor poster perkembangan akhlak pada kelas eksperimen dan kontrol selanjutnya diuji menggunakan rumus uji-t data homogen. Dari hasil uji-t diperoleh nilai $t_{\text {hitung }}$ $(=13,628)$ lebih tinggi daripada nilai. $\mathrm{t}_{\text {tabel }}(=2,160)$ maka $\mathrm{H}_{0}$ ditolak dan $\mathrm{H}_{\mathrm{a}}$ diterima. Dengan demikian, hasil penelitian ini membuktikan bahwa terdapat pengaruh metode bercerita Kisah Nabi terhadap perkembangan akhlak anak usia 5-6 tahun di RA Hamdaniyah.

\section{SIMPULAN DAN SARAN}

Pada penelitian ini diterapkan metode bercerita Kisah Nabi yang dibawakan oleh guru menggunakan alat peraga sehingga anak antusian untuk belajar dan perlahan akhlak anak ikut berkembang. Perkembangan akhlak yang diteliti merujuk pada beberpa indikator berikut: taat, tolong menolong, jujur, kasih sayang, sabar serta berani yang ditemukan mempunyai kriteria berkembang sesuai harapan dan berkembang sangat baik setelah diterapkan metode bercerita kisah nabi. Hasil penelitian juga membuktikan bahwa terdapat pengaruh metode bercerita Kisah Nabi terhadap perkembangan akhlak anak usia 5-6 tahun di RA Hamdaniyah.

Dari hasil penelitian disampaikan beberapa tindak lanjut atau saran, yaitu : (1) untuk kepala sekolah disarankan agar terus memberikan dukungan dalam menerapkan metode bercerita Kisah Nabi di sekolah, karena metode bercerita Kisah Nabi ini dapat mengasah kemampuan anak dan perkembangan anak terutama akhlak anak; (2) untuk guru disarankan dalam satu minggu harus ada menerapkan metode bercerita Kisah Nabi karena cerita ini sangat dapat mempengaruhi anak, karena pada hakikatnya anak ini mudah meniru dan cepat merekam apa yang diasah oleh gurunya. 3). Dalam mengembangkan aspek anak khususnya perkembangan akhlak anak, kepala sekolah lebih memberikan fasilitas yang sangat baik, karena disekolah ini pembelajarannya yang monoton membuat anak mudah 
http://jurnaltarbiyah.uinsu.ac.id/index.php/raudhah

bosan dan kurang berkembang akhlaknya, sehingga anak banyak yang tidak mau mendengarkan perintah gurunya, jika anak diberikan pembelajaran yang sangat menarik seperti metode bercerita ini, anak akan senang dan mau mendengarkan perintah gurunya

\section{DAFTAR PUSTAKA}

Abdul, R., \& Mamonto, E. (2016). Pengaruh Metode Bercerita Terhadap Kemampuan Menyimak Anak Di Kota Selatan Gorontalo,. Journal of Nonformal Education and Community Empowerment.

Abdurrahman. (2018). Meningkatkan Nilai-nilai Agama pada Anak Usia Dini melalui Pembinaan Akhlak. Jurnal Penelitian Keislaman.

Fatmawati, N. (2018). Pengaruh Metode Bercerita (Tentang Kisah-kisah Nabi dan Rosul) Terhadap Perkembangan Nilai Agama dan Moral Anak Usia 4-5 Tahun di RA Perwanida Raci Kecamatan Bangil Kabupaten Pasuruan. Jurnal AICIED.

Jaya, I. (2018). Penerapan Statistik Untuk Pendidikan. Medan: Perdana Publishing.

Khadijah. (2016). Pengembangan Kognitif Anak Usia Dini. Medan: Perdana Publishing. https://doi.org/10.1016/S0262-8856(98)00132-2

Maisarah. (2017). Hubungan antara Kemampuan Awal Penjumlahan dan Hasil Belajar Perkalian Pada Siswa Kelas II SD. Pembelajaran Inovatif Dalam Mencetak Generasi Yang Profesional Berkarakter Dan Unggul,.

Maisarah. (2019). Statistik Pendidikan. Medan: Akasha Sakti.

Mursid. (2015). Pengembangan Pembelajaran PAUD. Bandung: Remaja Rosdakarya.

Saepudin, A., \& Sudiarni, C. (2014). Penerapan Pendidikan Akhlak Mulia Dalam Mengembangkan Karakter Melalui Metode Bercerita Pada Anak Usia Dini. Jurnal Ilmu Pendidikan: Universitas Pendidikan Indonesia.

Suryana, D. (2014). Kurikulum Pendidikan Anak Usia Dini Berbasis Perkembangan Anak. Jurnal Pesona Dasar, 2(1).

Suyadi, \& Maulidya. (2015). Konsep Dasar PAUD. Bandung: Remaja Rosdakarya. Syafaruddin. (2011). Pendidikan Prasekolah Perspektif Pendidikan Islam dan Umum. Medan: Perdana Publishing. 